\title{
La verdad del hombre:Imago Dei Principios antropológicos de base para nuevos procesos educativos
}

Ramón Obdulio Lara ${ }^{1}$

Recibido en septiembre de 2014, aceptado en noviembre de 2014.

\begin{abstract}
Resumen
El autor analiza las principales líneas de comprensión del hombre desde la prespectiva cristiana: la línea teológica, la moral y la psicológica. En todas las líneas aparece una idea común: la comprensión del hombre como "imago Dei" (imagen de Dios). Propone, además, que esa comprensión antropológica debería ser el fundamento indispensable que ha de estar a la base de todo proceso educativo, lo que a su vez daría respuesta al grave problema de resquebrajamiento social que sufre el país.
\end{abstract}

Palabras claves:

Antropología, Imago Dei, moral, psicología, autotrascendencia, necesidades, valores, educación.

\begin{abstract}
Summary:
The author analyzes the main comprehension of man from a Christian point of view: the theological, moral and psychologist lines. All cited lines have an idea in common: comprehension of man as "imago Dei" (image of God). The author furthermore proposes that such anthropologic comprehension should be the foremost foundation that should be at the base of all education process, that at the same time it would give response to the chronic social deterioration problem of the country.
\end{abstract}

\section{Keywords:}

Anthropology, Imago Dei, moral, Psychology, self-trascendence, needs, values, education.

\section{Introducción}

La cultura occidental por muchas centurias se ha considerado mayoritariamente cristiana. Paradójicamente es en occidente donde se han fraguado, en los últimos siglos, las más sangrientas guerras que han dejado saldos de muerte nunca antes vistos. A inicios de este nuevo siglo y nuevo milenio se desató una especie de "guerra santa", que según algunos analistas puede considerarse como un

1.Ramón Obdulio Lara: Profesor de Teología de la Universidad Don Bosco, El Salvador. Email: ramón.lara@udb.edu.sv 
“choque de civilizaciones" (S. Huntington), y una de estas civilizaciones es la cristiana. El occidente cristiano sin duda evidencia elocuentes cotradicciones en cuanto su identidad. Si acercamos la mirada a nuestra realidad nacional descubriremos que la extragrande mayoría de salvadoreños se consideran cristianos. Sin embargo, la realidad cotidiana nos dice que somos una sociedad sumida en una vorágine de violencia de proporciones escandalosas, una sociedad con una larga estela de dolor y muerte. No hay en absoluto respeto por la persona y sus más elementales derechos.

Frente a esas evidentes contradicciones debemos preguntarnos sobre las causas de las mismas: ¿Por qué un occidente que se dice cristiano no vive y actua conforme a los valores que predicó Cristo? ¿Por qué un país mayoritariamente cristiano está sumido en esta espiral de muerte y dolor contradiciendo los valores cristianos de paz, amor y compasión? Podrán aducirse muchas razones que buscarían dar respuesta a estas cuestionantes, y por supuesto los análisis al respecto ya se han dado, y seguirán dándose. Sin embargo, consideramos que entre las muchas razones que pueden aducirse están sin dudas aquellas que tienen que ver con los principios antropológicos con que se construye el tejido social y cultural de los conglomerados. Eh ahí el motivo de este pequeño esfuerzo reflexivo. Nos proponemos analizar y profundizar en los fundamentos antropológicos pertinentes que posibiliten la reorientación de un nuevo tejido social y cultural de nuestro país, teniendo en cuenta que ya existe una matriz cultural cristiana en esta sociedad.

No dudamos que el reconocimiento de principios antropológicos claros y una definición más precisa del hombre, tal y como lo abordaremos en este estudio, es el primer paso para construir un nuevo tejido social. Es claro que la tarea de hacer ese nuevo tejido social pasa en primer lugar por la gran tarea educativa. La educación es la solución se dice. Pero no cualquier educación. Debe ser una que tenga de fondo una sana antropología, que se sustente en sólidos principios y claros fines. Un sistema educativo -currículum nacional y los procesos catequéticos eclesiales- que contenga una sólida antropología es parte de las soluciones para reconstruir esta resquebrajada realidad nacional. Sin embargo, en este estudio no abordamos en ese siguiente paso, o sea, cómo hacer de una más precisa antropología el fundamento del sistema educativo nacional. Ese deberá ser otro estudio. Nuestro esfuerzo y nuestro interés ha sido más limitado.

Utilizando el método analítico-sintético se ha pretendido alcanzar, como hemos dicho, un nivel suficiente de profundización para distinguir los elementos antropológicos concretos que sirvan de base para procesos educativos más sólidos. Dentro de una búsqueda prevalentemente bibliográfica, se intenta dar un bosquejo sintético del pensamiento antropológico en las áreas teológica, moral y psicológica. Tanto en el enfoque teológico dogmático como en el teológico moral jugamos con el concepto Imago Dei, es decir, el hombre 
comprendido como imagen de Dios, llamado a vivir su semejanza divina. El ser del hombre (enfoque dogmático) no debe separarse de su actuar (enfoque moral). La parte de la antropología psicológica centra su atención en dos propuestas convergentes de hermenéutica antropológica: la antropología de la vocación cristiana (L. M. Rulla) y la antropología del misterio (F. Imoda). Con ambas interpretaciones antropológicas se intenta indagar en los motivos psicológicos que hacen difícil al hombre vivir su identidad de Imagen de Dios y alcanzar la plenitud de su semejanza divina: las inconsistencias centrales y el no auto apropiarse del misterio presente en el hombre mismo.

\section{Imago Dei: desde la antropología teológica}

\subsection{Aproximación al concepto Imago Dei}

El hombre necesita conocerse cada vez más en profundidad para poder encontrar con mayor precisión su propio lugar en medio del universo creado. Las eternas preguntas ¿Qué o quiénes somos? ¿De dónde venimos o cuál es nuestro origen? ¿Hacia dónde vamos o cuál es nuestro destino?, son siempre preguntas acuciantes y validas en todo tiempo y lugar. Existen muchos intentos que buscan dar una más clara y precisa definición del hombre -las antropologías de distinto cortepero al final estos intentos no agotan la insondable profundidad de la identidad humana. En el contexto cristiano no cabe duda que es mediante la revelación divina que se logra alcanzar un mayor conocimiento de la propia identidad del hombre. Pero esta profundización antropológica a la luz del dato revelado, y en relación directa con el creador -antropología teológica-, últimamente se está redimensionando y se está planteando en relación directa con Jesucristo². Definitivamente el concepto «imagen de Dios» relaciona con mucha claridad cuanto se pueda decir sobre el hombre y cuanto se pueda decir sobre Cristo.

\subsubsection{Imagen de Dios en la Biblia}

La Biblia prohíbe enfáticamente hacer imágenes de Dios (Dt 4, 15; 5,8; Ex 20,4). La trascendencia de Dios es tal que nada lo puede representar, mucho menos es posible verlo cara a cara (Gn 32,31). Sin embargo, el dato escriturístico afirma que Dios creó al hombre lo «creó a su imagen y semejanza» $(G n 1,27 ; 5,1 ; 9,6)$. Además, la misma Escritura afirma que nadie en este mundo ha visto ni puede ver a Dios Padre, pero éste se da a conocer sólo en su Hijo Unigénito (Cfr. Jn $1,18)$. Porque el que «ve al Hijo ve al Padre» (Jn 14,9), ya que él es «la imagen de Dios invisible» (Col 1,15; 2Cor 4,4).

2. Cfr. Gaudium et Spes, 22. «En realidad el misterio del hombre sólo se esclarece en el misterio del Verbo encarnado». Según J.L. Ladaria, esta sería una clara indicación del camino a seguir en la investigación antropológica a la luz de la doctrina conciliar. Cfr. B. SESBÜÉ, Historia de los dogmas. El hombre y su salvación, II, España: Secretariado Trinitario, 1996, 114. El Papa Juan Pablo II recurría muy a menudo a estas ideas, tanto así que formaron parte fundamental de toda su antropología: Cfr. Redemptoris Hominis, 8. Cfr. también J.L. LORDA, Antropología Cristiana: del Concilio Vaticano II a Juan Pablo II, Palabra, Madrid, 1996, 86. 
Interesa sobre todo el sentido del término hebreo «sélem» (copia, reproducción exacta) para esclarecer el concepto «imagen» (eikon). Si alguien es imagen de Dios significa que es su representante personal ${ }^{3}$. Por tal motivo, ninguna cosa, objeto o figura puede representar a Dios; no puede haber una imagen de Dios fuera de aquella que Dios mismo ha querido plasmar: el hombre. Cualquier otra imagen o representación de Dios es un ídolo. Con el paso del tiempo, ya en el Antiguo Testamento, el concepto «imagen» crece y se amplia: La misma Sabiduría se identificará como «imagen de la bondad de Dios» (Sab 7,26), que no está «bajo Dios», sino junto a Él. Por tal motivo, en el Nuevo Testamento, la «imagen de Dios invisible» $(\mathrm{Col} 1,15)$ equivale a «Hijo de Dios» 4 .

\subsubsection{Imagen de Dios en los Padres de la Iglesia}

Como verdaderos maestros de la fe los Padres de la Iglesia ofrecieron a la Iglesia una rica y variada enseñanza sobre los distintos temas que conciernen a la misma fe. Evidentemente el concepto «imagen de Dios» fue tocado por ellos en sus escritos, homilías y catequesis. Es imposible recoger en pocas líneas toda la riqueza y variedad de tales enseñanzas, no obstante, podemos dejar constancias de algunas percepciones u opiniones que nos serán de mucha utilidad en la profundización de nuestro tema. Dos serían las perspectivas desde las cuales los Padres de la Iglesia trataron el tema de la «imagen de Dios»: la antropológica y la cristológica.

En la perspectiva antropológica es posible encontrar dos enfoques. El primero sería la visión integral del hombre: el hombre es imagen de Dios en toda su estructura constitutiva, es decir, no existe una dicotomía entre lo material o lo inmaterial o lo que sería la posterior distinción entre cuerpo y alma. El segundo enfoque sería la visión dicotómica: bajo la influencia del pensamiento griego y sobre todo platónico, se veía al hombre como un compuesto de alma y cuerpo y se adjudicaba la característica de ser imagen de Dios solo al alma ${ }^{5}$.

La perspectiva cristológica la ofrecen San Atanasio y San Hilario de Poitiers. Para ellos la imagen de Dios es el Verbo y el hombre ha sido creado «según la imagen»; «El Hijo de Dios es la imagen de Dios invisible y verdaderamente tomó carne de hombre... Todo hombre se incorpora a Cristo al asumir Él el cuerpo del

3. Cfr. AA.VV. Comentario Bíblico San Jerónimo, I, Madrid: Cristiandad, 1971, 67-72. AA.VV. Dizionario Esegetico del Nuovo Testamento, I, Brescia: Paideia Editrice, 1995, 1031-1040.

4. Cfr. AA.VV. Enciclopedia de la Biblia, IV, Barcelona: Ediciones Garriga, 1963, 107-115.

5. Cfr. L. F. LADARIA, «El hombre creado a imagen de Dios», en B. SESBÜÉ, Historia de los dogmas, II, 76-93. Según Ladaria los Padres Apostólicos y Apologetas, entre ellos de modo particular Justino, Ireneo y Tertuliano, tendrían una visión marcadamente unitaria del hombre, en quienes la dignidad del cuerpo es innegable. En el caso de Clemente de Alejandría y Orígenes darían prioridad al alma como la única que es imagen de Dios. La reflexión teológica posterior, sobre todo con las grandes sistematizaciones teológicas de la alta escolástica, permitió matizar esa constitución dicotómica de la identidad del hombre afirmando que ciertamente éste está constituido por un cuerpo y un alma pero estos elementos no existen separados: el hombre es cuerpo-alma. Sin embargo, la característica de ser imagen de Dio siempre quedó indicada en el alma. Cfr. Ibid., 100ss. 
hombre, a la vez Cristo se da a todos los hombres por su naturaleza divina, por ser imagen de Dios invisible ${ }^{6}$. En la misma línea, Ireneo y Tertuliano refieren a Cristo cuando hablan de la Imagen de Dios. Esta interpretación en clave cristológica del concepto «imagen de Dios» será retomada, como se verá, por los padres conciliares del Vaticano II, los cuales dejarán clara «la conexión del misterio del hombre con el misterio de Cristo» ${ }^{7}$.

\subsubsection{Imagen de Dios en el Magisterio Contemporáneo}

Hablar de magisterio contemporáneo es referirse a lo dicho por el Concilio Vaticano II así como a algunas consideraciones vertidas por el Papa Juan Pablo II, quien sin duda alguna hizo una interpretación y difusión de lo que en clave antropológico-cristológico dijo el Concilio ${ }^{8}$.

La reflexión antropológica del Concilio Vaticano II se condensa básicamente en la Constitución Pastoral Gaudium et Spes (GS). Al comienzo de esta constitución, los padres conciliares se hicieron la pregunta «pero ¿Qué es el hombre?» y enseguida responden:

Muchas son las opiniones que el hombre se ha dado y se da sobre sí mismo. Diversas e incluso contradictorias. Exaltándose a sí mismo como regla absoluta o hundiéndose hasta la desesperación. La duda y la ansiedad se siguen en consecuencia. La Iglesia siente profundamente estas dificultades, y, aleccionada por la Revelación Divina, puede darles la respuesta que perfile la verdadera situación del hombre, dé explicación a sus enfermedades y permita conocer simultáneamente y con acierto la dignidad y la vocación del hombre. La Biblia nos enseña que el hombre ha sido creado "a imagen de Dios", con capacidad para conocer y amar a su Creador, y que por Dios ha sido constituido señor de la entera creación visible para gobernarla y usarla glorificando a Dios. ${ }^{9}$

En los siguientes números los Padres Conciliares hablan del pecado, de la constitución del hombre como compuesto de alma y cuerpo, apuntan a la dignidad de la inteligencia, la conciencia moral y la libertad en el hombre. Dejan espacio entre los números 19 y 21 para hablar del ateísmo. Este capítulo uno de la GS termina con el famoso numero 22, titulado «Cristo, el hombre nuevo». Llama la atención este cierre cristológico que hacen los Padres Conciliares sobre la reflexión antropológica. Este cierre está diciendo con claridad que toda palabra dicha sobre el hombre encuentra su resonancia en Cristo, porque «el misterio del hombre solo se esclarece en el misterio del Verbo encarnado", porque "Cristo manifiesta el hombre al propio hombre», porque «El que es

6. C. BARBA AVILA, Teología de la Imagen de Dios en San Hilario de Poitiers, Navarra: EXCERPTA XLVI, 2004., 51.

7. Cfr. B. SESBÜÉ, Historia de los dogmas , 114.

8. Cfr. J.L. LORDA, Antropología Cristiana, 137ss.

9. GS, 12. 
imagen de Dios invisible es también el hombre perfecto, que ha devuelto a la descendencia de Adán la semejanza divina, deformada por el primer pecado». Según este planteamiento, para decir una palabra sobre el hombre ahora necesariamente debemos hablar de Cristo, quien es el «Hombre perfecto».

Recogiendo la teología paulina de los adames los padres conciliares hacen la contraposición en términos de «figura» y «manifestación». El primer Adán es figura o reflejo y el segundo es manifestación plena de la verdad de lo humano. Enseguida citan colosenses 1,15, donde San Pablo afirma que «Cristo es imagen del Dios invisible», para afirmar que «el hombre perfecto» solo es Cristo. Es posible pensar, por tanto, que así como en un espejo hay un reflejo y un reflejado, y que la imagen reflejada no tiene consistencia fuera de la verdad que refleja, así el hombre tiene su verdadera identidad o su verdadera consistencia solo frente a Cristo, en Cristo y con Cristo. La profundidad de la expresión «el verdadero hombre es Cristo» tiene alcances insospechados.

Por su parte, el Papa Juan Pablo II, como conocedor de primera mano del pensamiento conciliar ${ }^{10}$, hace eco de esta antropología de manera particular en su primera carta encíclica que tituló Redemptoris Hominis. Esta encíclica busca conjugar la antropología y la cristología en el concepto «redención»: uno es el redimido y el otro es el redentor. Para explicitar este encuentro entre el hombre y Cristo en términos de redención, el Papa recurre plenamente a la enseñanza conciliar; muestra de ello es la cantidad de citas directas a los documentos conciliares y sobre todo a la GS. Para el Papa el hombre necesita de un redentor, porque el hombre en sí mismo y por si mismo no encuentra la respuesta a sus más profundas aspiraciones. Solo Cristo puede responder a las profundas aspiraciones del hombre, las cuales no son sino aquellas ansias de eternidad y de profunda comunión con Dios, porque en Cristo Dios se ha acercado al hombre y en Cristo el hombre puede unirse a Dios ${ }^{11}$.

\subsection{El hombre creado a imagen de Dios}

Este breve recorrido, en aproximación al concepto «imagen de Dios», nos ha permitido constatar la innegable conexión entre la antropología y la cristología. Deja abierta además la posibilidad de hacer una mayor profundización de la identidad del hombre, vista justamente como imagen de Dios. Sin embargo, partiendo del dato revelado es fácil advertir que el hombre, aunque había sido creado a imagen de Dios, también es un ser caído, alguien que pecó. Cabe preguntarse ¿Qué significado tiene el concepto imagen de Dios dado al hombre en el contexto protológico? La constatación de la realidad del pecado ya desde

10. Cfr. Ibid. p. 85. Según Lorda, el cardenal Wojtyla sería uno de los redactores finales de esta primera parte de la Gaudium et Spes.

11. Cfr. Redemptoris Hominis, 11: «En Cristo y por Cristo, Dios se ha revelado plenamente a la humanidad y se ha acercado definitivamente a ella y, al mismo tiempo, en Cristo y por Cristo, el hombre ha conseguido plena conciencia de su dignidad, de su elevación, del valor trascendental de la propia humanidad, del sentido de su existencia». 
la protología, ¿Qué estaría indicando? ¿No dijo Dios que todo era bueno y que cuando creó al hombre vio que «era muy bueno»?

\subsubsection{El hombre creado}

El símbolo Niceno-Constantinopolitano comienza con la declaración de fe en «Dios, Padre Todopoderoso, creador del cielo y de la tierra, de todo lo visible y lo invisible» ${ }^{12}$. Esta afirmación evidentemente tiene su base en el relato del Génesis donde se afirma que «en el principio creó Dios el cielo y la tierra» (Gn $1,1)$. En este proceso creador, según el relato del Génesis, hay un momento culmen cuando dijo Dios: «Hagamos al ser humano a nuestra imagen, como semejanza nuestra...creó Dios, pues, al ser humano a imagen suya, a imagen de Dios lo creo...Vio Dios cuanto había hecho, y todo estaba muy bien» (Gn 1,2627.31).

Es evidente que en el pensamiento de los Padres de la Iglesia la idea de la creación del hombre tiene una profunda matriz cristológica. Para Tertuliano «el cuerpo del hombre fue modelado a imagen del cuerpo de Cristo y fue vivificado por el soplo que Dios le insufló» ${ }^{3}$. San Hilario, afirma que «Adán fue hecho según el modelo único de la imagen común entre el Padre y el Hijo, es decir, con naturaleza espiritual; pero, por otro lado, al ser hecho del polvo de la tierra (es decir, con cuerpo) indicaría que el Hijo se iba a encarnar ${ }^{14}$. Siempre en este sentido cristológico Ireneo también afirmará que el modelo según el cual el hombre ha sido modelado es Jesús: «Y la imagen de Dios es el Hijo, a cuya imagen ha sido hecho el hombre. He aquí por qué, en los últimos tiempos, se ha manifestado, para dar a entender que la imagen era semejante a Sí»» ${ }^{15}$.

También se ha podido constatar que la posterior influencia del pensamiento platónico hizo derivar la comprensión del hombre como una estructura compuesta entre alma y cuerpo. Esta visión dualista resta méritos a la corporalidad y deja al alma como la única portadora de la imagen divina. Sin embargo, el intento de definir al hombre bajo la perspectiva platónica seguramente nace porque este tipo de pensamiento explica con mayor claridad la constatación real de que en el hombre hay algo más que materia, es decir, el hombre no es solo carne o corporeidad. Esta mentalidad posibilitó, además, la posterior explicación de la condición pecadora del hombre. Y esto sobre todo amparándose en la teología paulina del «hombre de la carne y el hombre del espíritu». La carne será vista como la raíz del pecado y el alma será la verdadera identidad del hombre, y lo que el hombre debe cuidar y salvar.

\subsubsection{El hombre caído}

12. H. DENZINGER - P.HÜNERMANN, El Magisterio de la Iglesia, 338a ${ }^{\mathrm{a}}$. Ed., España: Herder, 2006, n. 150 (en adelante será citado DH).

13. C. BARBA AVILA, Teología de la Imagen de Dios, 80.

14. Ibid. p. 75.

15. B. SESBÜÉ, p. 79. Ladaria cita a san Ireneo en «Demostración de la predicación apostólica, 22». 
Cuando la Biblia habla de la creación del hombre inmediatamente une también el relato de la caída. La ubicación de la existencia del pecado en un contexto protológico puede llevarnos a pensar que el autor sagrado apunta a esa realidad ineludible de la experiencia humana: la existencia del mal y la comisión de actos de maldad por parte del hombre. En este sentido san Pablo habla con mucha claridad sobre el drama que vive el hombre en cuanto inclinado al mal: «En efecto, querer el bien lo tengo a mi alcance, mas no el realizarlo, puesto que no hago el bien que quiero, sino que obro el mal que no quiero» (Rm 7,1819). En este punto surge la pregunta ¿A caso el hombre no fue creado "bueno" por Dios? ¿Por qué el pecado ha de tener poder sobre el hombre?¿Dónde ubicar en este drama la libertad humana?

Que la raíz de este drama sea la misma libertad humana es admisible ${ }^{16}$. El hombre como imagen de Dios tiene una libertad que tiende a la infinitud. Además, el hombre para hacer buen uso de su libertad necesita de un conocimiento que con la misma infinitud dirija la voluntad hacia donde los anhelos de la libertad la impulsan. Pero en su condición creatural el hombre tiene el límite del «no conocimiento». Creaturalmente el hombre no puede tener «un infinito conocimiento». No puede tener un conocimiento infinito por causa de su «materialidad» y su «temporalidad». Espacio y tiempo condicionan-limitan «el conocer» ${ }^{17}$.

Es fácil comprender entonces por qué la gran tentación de la que se habla en el Génesis está directamente relacionada con el conocimiento: pues ser como Dios es justamente conocer como Dios. El engaño consiste en la pretensión de conocer como Dios, siendo que creaturalmente es imposible. Sin olvidar que el hombre es «imagen y semejanza» de Dios, es decir, que tiene un parentesco con Dios manifestado en su permanente tensión a la infinitud, es posible comprender su ilimitada búsqueda de libertad y su insaciable sed de conocimiento ${ }^{18}$. Así pues, los impulsos de una libertad infinita unida a un conocimiento limitado, conducen al hombre a la condición de «permanente elector», el hombre siempre debe estar eligiendo. Dios no tiene que elegir, porque lo conoce todo. Esa condición de elector es causa de una angustia y un dolor existencial.

Pues bien, este hombre abatido por este dolor-angustia, muchas veces elige erróneamente cuando es impulsado por los influjos de infinitud que su propia libertad le incita. ¿Qué es lo que en definitiva la libertad le impulsa alcanzar al hombre? No hay duda que el hombre es impulsado por su libertad hacia su plena realización como persona, es decir, a la perfecta comunión y contemplación

16. Cfr. Catecismo de la Iglesia Católica, 397.

17. J. BOORJAMRA, «Original sin according to St Maximus the Confessor» in Saint Vladimir's Theological Quarterly 20 (1976) 19-30. Los siguientes párrafos han sido escritos a la luz de este artículo.

18. Rahner con el término «trascendente» resume estas ideas. Cfr. K. RAHNER, Oyentes de la Palabra, Barcelona: Herder, 1967, 73ss. 
de $\operatorname{Dios}^{19}$. Pero al desconocer el camino de esa plena realización, el hombre muchas veces se equivoca en su elección. Ese error, que hace sufrir personal y socialmente, se llama pecado.

El pecado, visto desde esta perspectiva, sería el resultado de la elección errada del hombre que busca su máxima realización. La Escritura habla con mucha insistencia sobre esa triste experiencia de «pecado» que ha acompañado al hombre desde los inicios de su existencia. A esa experiencia de pecado desde los orígenes se le ha dado el nombre de Pecado Original.

Pero esta antropología del hombre caído invita más bien a profundizar sobre el plan creacional de Dios. Si el hombre fue creado con esa tensión de infinitud pero limitado en su condición de creatura podemos pensar que en el plan de Dios había algo más. La exclamación de san Pablo resuena con mayor fuerza y claridad: «¡Pobre de mí! ¿Quién me librará de este cuerpo que me lleva a la muerte?» $(\mathrm{Rm} 7,24 \mathrm{a})$.

\subsection{Cristo imagen de Dios invisible}

No hay duda que el Concilio Vaticano II propuso una visión antropológica radicalmente dependiente de Cristo: «el misterio del hombre sólo se esclarece en el misterio del Verbo encarnado» (GS, 22). La grandeza del hombre como culmen de la creación, tal como el salmista la canta: «a penas inferior a un Dios lo hiciste coronándolo de gloria y esplendor» (Sal 8,6), lo mismo que su miseria y su pecado: «mira que nací culpable, pecador me concibió mi madre» (Sal $50,7)$, tiene su definitivo culmen y consumación en Cristo: «¡Gracias sean dadas a Dios por Jesucristo nuestro Señor!» (Rm 7,24b).

\subsubsection{Dios hecho Hombre}

Que Jesucristo es Dios verdadero en cuanto consustancial al Padre lo confirmó Nicea (325 d.C.) y que es Hombre verdadero en cuanto consustancial a todos los hombres lo define Calcedonia (451 d.C. ${ }^{20}$. Esa perfecta divinidad y a la vez perfecta humanidad presentes en Jesucristo lo ponen en el quicio de una nueva antropología: «La novedad que la antropología cristiana nos aporte tendrá que ver por tanto, de una manera esencial, con la novedad de Cristo „21. Según Ladaria, se ha hecho «un primer movimiento que va de Adán a Cristo, para entender lo que Cristo es, pero muy pronto, a la luz de la fe, se ha hecho necesario el paso contrario para entender la profundidad del misterio humano... de Adán a Cristo y de Cristo a Adán, dos movimientos relacionados, que se implican mutuamente ${ }^{22}$. Citando a Von Balthasar, Ladaria afirma que Cristo

19. El «desiderium videndi Deum» analizado por H. de Lubac y toda su teoría del «sobrenatural» explica mayor amplitud esta idea. Cfr. H. DE LUBAC, El Misterio de lo sobrenatural, Madrid: Encuentro, 1991.

20. DH, 301.

21. L.F. LADARIA, Jesucristo, Salvación de todos, San Pablo, Madrid, 2007, 46

22. Ibid., 30. 
«como redentor él está después del pecado, pero como imagen y cabeza de la creación está antes» ${ }^{23}$.

Los Padres de la Iglesia dejan claro que entre Adán y Cristo hay una correspondencia directa como creatura y creador, pero sobre todo, resaltando la visión de una creatura que es modelada a imagen de Aquel que es la vedad, perfección y consumación de lo creado. Las siguientes tres afirmaciones dadas por san Ireneo, Tertuliano y san Hilario respectivamente son ilustrativas:

De esta tierra, pues, todavía virgen, Dios tomó barro y plasmó al hombre, principio del género humano. Para dar, pues, cumplimiento a este hombre, asumió el Señor la misma disposición suya de corporeidad, que nació de una Virgen por la Voluntad y por la Sabiduría de Dios, para manifestar también él la identidad de su corporeidad con la de Adán, y para que se cumpliese lo que en el principio se había escrito; el hombre a imagen y semejanza de Dios [...] Pronunció Dios en plural 'hagamos'...¿Con quién creaba al hombre, y a quien lo hacía semejante? Con el Hijo, que iba a revestirse del hombre, y con el Espíritu, que iba a santificar al hombre; hablaba con ellos en la unidad de la Trinidad como ministros y testigos. Después el siguiente pasaje distingue entre las personas: Dios hizo al hombre, lo hizo a imagen de Dios (Cfr. Gn 1,17). ¿Por qué no dice 'a su imagen' si era uno el que hacía y no había otro a imagen del cual lo hacía? Pero había uno a imagen del cual hacía, es decir, el Hijo, el cual, debiendo ser el hombre más cierto y más verdadero (homo futurus certior et verior), quiso que fuere llamado hombre su imagen que entonces iba a formar del barro, imagen y semejanza del verdadero [...] Adán, por su mismo nombre, prefigura el nacimiento del Señor, pues el nombre hebreo de Adán, que en griego se traduce como 'ge pyrra', significa en latín 'tierra de color de fuego', y la Escritura acostumbra a dar el nombre de 'tierra' a la carne del cuerpo humano. Esta carne, que, en el Señor, nació de la Virgen por el Espíritu, transformada en una forma nueva y extraña a sí misma, ha sido hecha conforme a la gloria espiritual, según el Apóstol: El segundo hombre viene del cielo (1Cor 15,47), y es el Adán celeste, porque el Adán terrestre es imagen del que había de venir (Rm 5,14). ${ }^{24}$

Esta intuición de los Padres de la Iglesia, recogida sustancialmente por el Concilio Vaticano II en la Gaudium et Spes 22, nos permite avanzar en nuestra argumentación. La perfección de la que hablaba el Génesis no era del primer «Adán», sino la del «Verdadero Adán» que existía antes de todos los siglos, pero que iba a venir en la carne al «llegar la plenitud de los tiempos» (Gal 4,4).

23. Ibid., 31.

24. Ibid., 51-52. Notas tomadas textualmente según la citación de Ladaria. 


\subsubsection{Hombre redimido}

El pecado indica la condición imperfecta del hombre en cuanto creatura, necesitado de aquel que lo rescate y lo eleve a su verdadera dignidad. El redentor sería el «lugarteniente», la Imagen (Sélem) perfecta y consumación verdadera de lo que el hombre puede y debe llegar a ser: Cristo. Redimir al hombre quiere decir elevarlo a su verdadera y perfecta identidad. Por tanto, y siguiendo las intuiciones de Ladaria, «el hombre perfecto es Cristo y sólo en él se descubre lo que significa la perfección de la humanidad». ${ }^{25}$ Esa perfección en Cristo no lo distancia de nuestra condición imperfecta, al contrario, si en Cristo hay una perfección que en nosotros no se encuentra, significa que esa humanidad de Cristo es paradigmática, o sea, solo en Cristo nuestra humanidad es perfecta. Calcedonia al definir la perfecta humanidad de Cristo, en sintonía con el autor de la carta a los Hebreos $(4,15)$, declara la impecabilidad de Cristo. Ladaria afirma: «precisamente en virtud de su única e irrepetible comunión con Dios en la unión hipostática, esta humanidad -de Cristo- no queda absorbida ni disminuida, sino elevada y potenciada hasta el máximo de su autonomía creatural...la mayor cercanía de Dios lleva a la mayor plenitud del hombre, nunca al revés». ${ }^{26} \mathrm{El}$ pecado no es parte constitutiva de la naturaleza humana, por eso la humanidad de Cristo es sin pecado, porque es la verdadera y perfecta humanidad. En este sentido, es el hombre el que tiene una carencia que sólo en Cristo la puede suplir.

La efectiva redención para la humanidad consiste en participar de la perfección en Cristo. Puesto que Cristo «recapitula todas las cosas en sí» (Ef 1,10), la perfección ya está dada, falta solo apropiársela. Para apropiarse esa perfección sólo es posible mediante la identificación de nuestra voluntad a la voluntad de Cristo, de tal manera que al final ya no se viva para sí mismo, sino en Cristo: «y no vivo yo, sino que es Cristo quien vive en mí» (Gal 1,20). Esta perfecta identificación y comunión con Cristo se realiza día a día en la vida del hombre mediante la acción del Espíritu de Cristo: «el que nos marcó con su sello y nos dio en arras el Espíritu en nuestros corazones» (2Cor 1,22). Esa voluntad nuestra sujeta a la de Cristo manifestada en la obediencia a Dios, según el autor de la carta a los Hebreos, es la «causa de la salvación» (Hb 5,9). Pero además, «con la resurrección, Jesús es constituido Hijo de Dios en potencia (Cfr. Rom 1,3-4), Señor de todo (Fil 2,11)...la salvación de los hombres se encuentra en relación intrínseca con la plenitud de la humanidad de Cristo en la resurrección» ${ }^{27}$. A partir de la resurrección Jesús se convierte en el dador del Espíritu (Cfr. Jn 20,22), quien será de ahora en adelante el que llevará a culmen toda la obra comenzada por Jesús (Cfr. Jn 14,16).

Cristo resucitado (humanidad perfecta) da su Espíritu que «enseñará todo»lo

25. L.F. LADARIA, Jesucristo, 56.

26. Ibid., 55. En cita pie de página, Ladaria recuerda la famosa frase de Rahner: «La dependencia radical de Dios no crece en proporción inversa, sino directa, con la verdadera autonomía ante él».

27. Ibid., 95. 
que el hombre caído necesita saber, y «recordará todo lo que Jesús ha dicho» (Jn 14,26) para vivir como verdaderos Hombres, como Hombres Perfectos, ya que la vocación de todos los seres humanos es la de «ser perfectos como el Padre celestial es perfecto» (Mt 5,48).

\section{Imago Dei: desde la antropología Moral}

El análisis teo-antropológico del concepto Imago Dei nos ha llevado a concluir que la vida del hombre encuentra sólo en Cristo el camino de verdadera y plena identidad: «En realidad, el misterio del hombre sólo se esclarece en el misterio del Verbo encarnado». ${ }^{28}$ Debemos por tanto analizar cómo el hombre en Cristo ha de vivir plenamente su identidad icónica, o sea, su perfecta humanidad. En otras palabras, debemos entrar al campo de la antropología moral. El actuar humano obviamente encuentra un nuevo cause cuando se vive en una plena adhesión con Cristo. Ya que como afirma S. Bastianel, «el hecho de creer en Jesucristo interesa a la vida de la persona en su totalidad, afecta a su entera responsabilidad en los diversos niveles de sus decisiones libres. Es más, el comportamiento moral se presenta justamente como el lugar de verificación de la sinceridad de la adhesión de fe». ${ }^{29}$

\subsection{El ser del hombre}

\subsubsection{Icono de Dios: Sujeto y Objeto de la moral}

La antropología teológica no sólo nos lleva a afirmar que el hombre encuentra su verdadera identidad en Cristo, sino también a afirmar que Cristo es «el hombre perfecto ${ }^{30}$, puesto que «el es Imagen de Dios invisible, Primogénito de toda la creación, porque en él fueron creadas todas las cosas [...] él existe con anterioridad a todo, y todo tiene en él su consistencia» (Col 1, 16-17). El hombre, unido a Cristo, es verdadera y perfecta imagen de Dios. Con mayor precisión J. R. Flecha afirma:

El hombre es, por su creación, imagen de Dios y está llamado a reproducir en la vida a Jesús, el Cristo, imagen e icono definitivo de Dios. Siguiendo las huellas de los textos conciliares, tanto la doctrina de la Iglesia como la Antropología teológica como la Teología Moral han retomado una y otra vez el tema de la imagen de Dios para fundamentar las exigencias éticas del respecto al hombre y la promoción de la justicia. ${ }^{31}$

La tesis de Flecha es que si el hombre es imagen de Dios, él «desempeña una función de visir y representante ante los animales, las plantas y hasta los astros del firmamento; como imagen de Dios que se encuentra con otros seres humanos,

\section{GS, n. 22.}

29. S. BASTIANEL, «Especificidad de la moral cristiana» en F. COMPAGNONI - G. PIANA - S. PRIVITERA, dirs., Nuevo diccionario de teología moral, Madrid: Paulinas, 1992, 601.

30. GS, n. 22.

31. J.R. FLECHA ANDRÉS, Teología moral fundamental, Madrid: BAC, 1994, 146. 
complementarios, cercanos como la propia carne y los propios huesos, pero que son, también ellos, imagen del único Dios». ${ }^{32}$ En otras palabras, como imagen de Dios el hombre es sujeto de la moral.

La antropología de la iconalidad nos recuerda que el hombre no es puramente una realidad sagrada, aunque tampoco una realidad exclusivamente profana. Representante de Dios -imagen de Dios-, no es un dios, sin embargo. $Y$ ningún ser humano podrá, en consecuencia, arrogarse prerrogativas divinas, pretendidamente fundadas en su estatura, su fuerza, su posición social o económica, el color de su piel o sus ideales políticos. Desde este punto de vista, la comprensión del ser humano como imagen de Dios aporta la base suficiente para una definitiva desacralización de las dignidades y aspiraciones humanas, así como una vigorosa crítica profética contra semejantes pretensiones. ${ }^{33}$

Por eso el hombre es también objeto de la moral. Es decir, «el tema de la imagen de Dios sugiere un comportamiento del hombre, orienta también el comportamiento moral para con el hombre. Si el ser humano es y se comporta como imagen de Dios, según queda dicho, ese ser humano merece también el respecto que se debe al que es imagen de Dios». ${ }^{34}$ Por ser imagen de Dios el hombre es persona y tiene una alta dignidad.

\subsubsection{Icono de Dios: Persona y Dignidad}

El hombre es una realidad personal. No es un ser solitario, una mónada aislada. Cada hombre está indefectiblemente unido con los demás hombres. El hombre, pues, es un ser relacional por naturaleza y por ser cristiano es además vinculado: "creer en Dios y cerrarse, aunque sea a un hombre solo, es contradicción. "La relación del hombre para con Dios Padre y la relación del hombre para con los hombres sus hermanos están de tal forma unidas que la Escritura llega a decir: el que no ama, no ha conocido a Dios" (1Jn 4,8)»35. Como persona el hombre tiene algunas propiedades que le son esenciales: individualidad, inabarcabilidad, inacabamiento, inaccesibilidad e innumerabilidad ${ }^{36}$. La noción de persona, dice Vidal, «juega un papel decisivo en la moral: el sujeto y el objeto de la moral es la persona». ${ }^{37}$

En el encuentro con el tú se realiza efectiva y circunstanciadamente el yo. La creación de la nostridad, está en íntima relación con la aparición de la tuidad y la yoidad. La dignidad de la persona humana se abre así al diálogo y respeto e todas las personas. La fe cristiana, aun admitiendo la grandeza y dignidad de esta relación horizontal, la reconoce como insuficiente cuando se considera

32. Ibid., 149.

33. J.R. FLECHA ANDRÉS, Moral de la persona, Madrid: BAC, 2002, 23.

34. ID., Teología moral fundamental, 151.

35. A. BANDERA, Comunión eclesial y humanidad, Salamanca: San Esteban, 1978, 18.

36. Cfr. M. VIDAL, Moral de actitudes, I, Madrid: PS Editorial, 1981, 249.

37. Ibid. 
como puramente intrahistórica. El hecho de la muerte interpela a la solidaridad humana para confesar una fraternidad metahistórica.

En la moral de la persona, la relación con "los otros" se hace especialmente problemática desde el punto de vista ético, cuando la moral de la alteridad no es capaz de superar las limitaciones de una mera ética de alienidad. Con razón puede afirmar la tradición judeo-cristiana que en cada prójimo que es maltratado, quien sufre es un hermano, un miembro de la única gran familia humana. La objetivación de los otros y su reducción al ámbito de los medios e instrumentos ha sido denunciada por todos los humanismos, que, a su vez, han tratado de fundamentar una ética de la relación constructiva del hombre con los otros hombres. ${ }^{38}$

Flecha, además, nos invita a reconocer en la persona humana una insondable dignidad. Como ya hemos insinuado, el hombre no sólo es sujeto de la moral, sino también objeto de la misma. La dignidad que tiene el hombre, por ser imagen de Dios, hijo en el Hijo, merece el más genuino y amplio respeto. El hombre por tanto no puede ser cosificado, como la generalizada concepción de la sexualidad contemporánea lo reduce; no puede ser instrumentalizado y reducido a mera pieza del mercado, como la más fuerte corriente económica actual de hecho lo hace; no puede ser explotado, marginado, y discriminado, social y culturalmente, como en muchas latitudes efectivamente sucede, porque todos los hombres tienen la misma dignidad.

No debemos olvidar, en fin, que el hombre llega a reconocerse como persona (auto afirmación) y a reconocer al otro como tal (afirmación) mediante el proceso de personificación. Este proceso inicia con el «autodescubrimiento», o sea, indagando sobre sí mismo: «¿Quién soy yo?». El proceso de auto conocerse es importantísimo para la autorealización y la autotrascendencia ${ }^{39}$. Sin un profundo autoconocimiento no es posible llegar al conocimiento de los propios límites y de su necesaria y serena aceptación; no se llega al conocimiento de las cualidades y el consecuente humilde cultivo. Por eso se puede decir, también, que la personalización es un proceso de educación. Es decir, es necesario hacer un camino de desarrollo de lo que es la propia identidad, de la conciencia del propio ser, del yo. La verdadera educación, pues, es personalizar: autoconocerse, aceptar serenamente los límites y cultivar humildemente las cualidades. Sólo dando estos pasos es que se arriba a una auténtica afirmación de la persona del otro y, a la vez, a un encuentro enriquecedor con éste. Con lo dicho hasta el momento se afirma la identidad del ser humano como un ser de encuentro, de interrelación.

\subsubsection{Icono de Dios: Ser de encuentro}

38. J.R. FLECHA ANDRÉS, Moral de la persona, 25-26.

39. Cfr. L. M. RULLA, Antropologia della vocazione cristiana, I, Casale Manferrato: Piamme, 1985, 188. Argumento que trataremos más adelante. 
Esta identidad del hombre tiene una íntima relación con la identidad «personal», vista brevemente en el parágrafo anterior. Si el hombre es persona está abierto y lanzado al otro. La alteridad es una dimensión constitutiva de su ser. Por ser reflejo de lo divino en lo histórico, el hombre tiene la condición connatural de la comunionalidad: el hombre es persona, es relación, es comunión, como Dios que es trinidad. Por estar indefectiblemente unido con el otro, el hombre no encuentra su verdadera identidad y perfecta realización si no es en comunión. El aislamiento, el egoísmo, despersonalizan y empobrecen la grandeza del hombre.

Todos tenemos una historia. Las relaciones interpersonales son encuentros de historias. En la historia de cada persona hay experiencias que han marcado la vida: experiencias en la infancia, adolescencia y juventud, por ejemplo, pero que quedan escondidas en el oscuro mundo del inconsciente. No es fácil conocer la propia historia, jimaginémonos pretender conocer la historia del otro! Todo hombre, por tanto, tiene una historia intangible, que es efecto de las experiencias intangibles de la vida, aquellas que no son posibles de dominar o determinar porque son inconscientes. En medio de la historia personal (oculta, inconsciente e intangible), está la historia de la salvación obrada por Dios. La gracia de Dios acompaña la historia de cada persona, la purifica y la perfecciona. Por medio de su gracia, su presencia y cercanía, Dios ha diseñado al hombre como su imagen y semejanza. Y como hemos mencionado en el párrafo anterior, el hecho de ser imagen de Dios confirma la identidad relacional de cada ser humano, pero por esa historia de gracia, tal relacionalidad es transformada.

En este nuevo cuadro de relacionalidad aparece en primer plano el reconocimiento de la dignidad, «preciosidad», y valor de cada hombre. El trato entre los seres humanos debe ser, por tanto, de un absoluto respeto, debido a la inmensurable dignidad que le proviene de su ser imago Dei. El único modo válido como pueden relacionarse los hombres entre sí es en términos de donación: cada uno es un don para el otro. Por ser tales, solo se pueden dar y recibir recíprocamente, nunca negociar o pretender tasar un valor, pues como valor el hombre es inconmensurable. El otro aspecto que resalta en el cuadro de la relacionalidad del hombre es el amor. El hombre es imagen de Dios, que es relacionalidad, y por tanto se realiza como ser en relación con otros. Dios es además amor. Como imagen de Dios el hombre encuentra su autorealización amando. «El ser humano se trasciende en su actuación, pero su realización plena no se da sino en la dimensión más honda de la libertad: el amor. La persona se humaniza en recibir y dar amor».40

Pero se puede vivir en relacionalidad o en aislamiento. Puede elegirse vivir en el amor o en contra del amor. Sabemos que el campo de la relacionalidad

40. H. M. YÁNEZ, Esperanza y Solidaridad. Una fundamentación antropológico-teológica de la moral cristiana en la obra de Juan Alfaro, Madrid: Publicaciones UP Comillas, 1999, 392. 
es inevitable. Estamos en relación obligadamente. La clave está en cómo relacionarnos: como relación enriquecedora o empobrecedora. Si nos relacionamos desde las virtudes nos enriquecemos, si desde los vicios nos empobrecemos. La relacionalidad puede ser, pues, virtuosa-enriquecedora o viciosa-degradante. Esta relacionalidad enriquecedora dependerá, por tanto, de la vivencia del amor como fuente de todas las virtudes. Para ello el hombre necesita abrirse al trascendente, entrar en comunicación con la realidad de Dios. El modo como el hombre entra en contacto con Dios es mediante el culto y la adoración. Sólo mediante una adecuada experiencia de comunicación con Dios, en verdadera adoración, que no es otra cosa que abrirse al Don de Dios (el Espíritu Santo) y vivir según las mociones de este Espíritu. Mediante ese culto espiritual, en verdadera adoración, el hombre entra en una auténtica y edificante relacionalidad. Su actuar también será definitivamente replanteado.

\subsection{El Hacer del hombre}

\subsubsection{Actuar según la ley}

El hombre en su identidad de imagen de Dios, elevado a su máxima expresión de lo que es esa identidad mediante la gracia salvadora dada por Cristo, tiene las herramientas necesarias para actuar conforme a esa dignidad. Sin embargo, aun siendo agraciado y dotado de la presencia divina mediante la acción del Espíritu Santo, el hombre necesita de la presencia pedagógica de la ley. La ley está puesta como el primer paso que debe dar el hombre hacia la consecución de la perfecta identidad icónica que sólo alcanza mediante el auxilio de la gracia. Por eso la ley tiene un rol importante en la vida del cristiano. Obviamente que el papel de la ley se limita a ser instrumento de la gracia no su sustituta (Cfr. Gal $3,24)$. Al final el hombre, mediante la gracia, es inducido a vivir sólo la ley de Cristo $^{41}$. Pero siempre ley.

Dios, siempre en un acto de gracia, ha hecho la ley (derecho divino) que presenta al hombre en algunos casos como ley natural (derecho natural) y en otros como ley revelada (derecho revelado). Como ley natural, escrita en el corazón del hombre (Cfr. Rm 2,15), está contenida en la naturaleza misma del hombre. Ésta ciertamente puede ser reconocida con la razón, pero no puede ser actuada sin la gracia. Por eso, el acto personal de fe, bajo el impulso de la gracia, conduce a la decisión que, siguiendo la ley natural en un dado comportamiento, cumple la naturaleza propia del hombre. ${ }^{42}$

El hombre movido por su propia razón construye a la vez el edificio legal que le sirve para una mejor convivencia, dada su naturaleza relacional. Las leyes creadas por el hombre para esa armónica convivencia social forman parte del llamado «derecho positivo». Este, sin embargo, debe reflejar fundamentalmente

41. Cfr. B. HÄRING, La ley de Cristo, I, Barcelona: Herder, 1963, 431-449.

42. Cfr. G. GHIRLANDA, Il diritto nella Chiesa. Mistero di comunione, Roma: San Pablo, 1990, 33. Cfr. tambien B. HÄRING, La ley de Cristo, I, 271-324. 
lo que ya contiene la ley natural. Además, la ley natural tiene la luz del derecho revelado, o sea, aquellos principios y valores fundamentales que Dios ha querido revelar y que prácticamente están contenidos en las Sagradas Escrituras. Y siendo que las Sagradas Escrituras conducen a un punto concéntrico, es decir, Cristo, podemos decir con mucha franqueza que toda ley, sea natural o sea positiva, es y debe ser reflejo de la ley de Cristo. Cristo se convierte en el parámetro esencial de todo el actuar humano y, específicamente, cristiano. Llevar al hombre a identificarse plenamente con Cristo, a vivir la vida en Cristo, es el papel y objetivo de toda ley.

En su papel pedagógico, la ley depende de la gracia, pues sin ella la ley se convierte en opresión y carga inútil. Esa combinación de la ley y la gracia posibilitan la vida cristiana. El cristiano no vive bajo el yugo de la ley, pero tampoco vive sin ley. El cristiano ha superado la ley en cuanto que auxiliado con la gracia hace de la ley un camino sereno de madurez y autenticidad. Para el cristiano la ley no es una carga pues la lleva inscrita en el corazón; no es una obligación pues la cumple espontáneamente como parte natural de su ser. Pero esa ley que cumple y vive el cristiano es más que preceptos, pues sobre todo es un conjunto de valores esenciales que orientan la manera de actuar y de vivir.

\subsubsection{Actuar según los valores}

Ser imagen de Dios para el cristiano es ser reflejo vivo de la verdadera imagen de Dios en la tierra: Cristo. La gracia de Dios empuja al hombre a reproducir esa perfecta imagen divina en el diario vivir. Quien actúa graciosamente en favor de los hombres en el aquí y ahora es el Don que el Padre junto con el Hijo envían: el Espíritu Santo. El Espíritu es quien transforma la ley en instrumento de vida, alejándola de su ser causa de maldición (Cfr. Gal 3,10). Agraciados por «el amor de Dios que ha sido derramado en nuestros corazones por el Espíritu que nos ha sido dado» $(R m 5,5)$ podemos llevar una vida digna según la condición de hijos de Dios, para dar los frutos de esa vida según el Espíritu (Cfr. Gal 5,22).

Una vida fructuosa según el Espíritu permite pasar del legalismo, que tanto denostaba san Pablo, a una experiencia de gracia guiada por valores fundamentales enseñados por el mismo Señor. Cristo lleva la ley a su plenitud: lo que la ley de la alianza sinaítica apenas insinuaba, encuentra plena perfección en la persona del Hijo y en los valores del Reino que viene a proclamar y a instaurar ${ }^{43}$. Es posible decir que con Cristo la moral ha de pasar desde una visión legalista hacia una axiológica. Al respecto la Pontificia Comisión Bíblica invita a revisar el mismo decálogo desde la óptica axiológica, que tiene siempre aún después de Cristo una validez vigente.

Nada nos impide de traducir en modo diferente, pero no menos fiel, el contenido

43. Cfr. PONTIFICIA COMISIÓN BÍBLICA, Bibbia e Morale. Radici bibliche del 'agire cristiano, Ciudad del Vaticano: Editrice Vaticana, 2008, 62-112. 
de la ley israelítica en términos de una moral de valores (o axiológica). Lo cual evidencia que, transcrito en este modo, el Decálogo adquiere una fuerza de claridad y de llamada mucho más grande para nuestro tiempo. En realidad, no sólo no se pierde nada en este cambio, sino que hay una ganancia enorme en profundidad $^{44}$.

En fin, la comisión propone la lectura axiológica del decálogo bajo los siguientes valores: el absoluto, la reverencia religiosa, el tiempo, la familia, la vida, la estabilidad de la pareja marido y mujer, la libertad -la comisión aclara que el séptimo mandamiento refiere más al secuestro o privación de libertad personal y no tanto al robo de objetos materiales-, la reputación, la casa y las personas humanas que ahí pertenecen, la casa y los bienes materiales. Cada uno de estos valores abre a un «programa» o sea una tarea moral nunca cumplida.

Las afirmaciones siguientes, introducidas por verbos, ilustran la dinámica que viene generada por el seguimiento de cada uno de estos valores. Tres valores verticales (consideran la relación de la persona con Dios):

1. Dar culto a un único absoluto;

2. Respetar la presencia y la misión de Dios en el mundo (lo que el "nombre" simboliza);

3. Valorizar la dimensión sagrada del tiempo.

Siete valores horizontales (consideran la relación entre las personas humanas):

1. Honrar la familia;

2. Promover el derecho a la vida;

3. Mantener la unión de la pareja marido y mujer;

4. Defender el derecho para cada uno de ver la propia libertad y dignidad respetada por todos;

5. Preservar la reputación de los otros;

6. Respetar las personas (que pertenecen a una casa, una familia, una empresa);

7. Dejar al otro sus propiedades materiales.

Analizando los diez valores presentes en el Decálogo, se nota que ellos siguen un orden de progresión decreciente (del valor prioritario a aquel menos importante); Dios al primer puesto y las cosas materiales al último; y, al interior de las relaciones humanas, se encuentra al inicio de la lista familia, vida, matrimonio estable. ${ }^{45}$

Transcribimos esta amplia citación del documento de la Pontificia Comisión Bíblica porque en ella encontramos un gran llamado a releer los diez mandamientos, y la ley en general, en términos de valores, bajo una visión axiológica, y con una

44. Ibid., 44.

45. Ibid., 44-45. 
visión más positiva antes que impositiva. Además, el documento insiste en que una visión axiológica puede ser un lenguaje más apropiado ante la sensibilidad moral de nuestro tiempo.

Por último, centrémonos en el actuar según los valores fundamentales que surgen a partir del seguimiento del Cristo: la vida teologal manifestada sobre todo mediante la solidaridad y la esperanza. Ciertamente que la fe, la esperanza y el amor son las dimensiones totalizantes de la existencia cristiana. ${ }^{46}$ De entre las virtudes teologales es el amor el fundamento teologal de la ética cristiana. ${ }^{47}$ Pero el amor tiene un rostro concreto, mediante el cual se manifiesta activamente en el diario vivir cristiano: la solidaridad ${ }^{48}$. Junto a la caridad/solidaridad, también la vida cristiana tiene la característica de ser una vida sellada con el signo de la esperanza: «en esperanza fuimos salvados» $(\mathrm{Rm} 8,24) .{ }^{49}$ Pero esta esperanza implica el compromiso por la fraternidad y la justicia, ya que es una esperanza activa, comprometida: «la esperanza cristiana, lejos de oponerse a las esperanzas del hombre en el mundo o de destruirlas, las integra y orienta en el sentido de su movimiento hacia lo nuevo y lo último. [...] Si la esperanza funda la existencia total del hombre en la existencia total de Cristo, adquiere una apertura radical al mundo y a la historia precisamente en Cristo». ${ }^{50} \mathrm{La}$ lucha por la justicia y el empeño por las liberaciones humanas son signos de una sólida esperanza. La vida cristiana, pues, es un actuar en esperanza solidaria y en solidaridad esperante. ${ }^{51}$ Todos estos son valores insuperables que orientan el actuar del hombre.

\subsubsection{El papel de la conciencia}

«En la conciencia es donde acaece la "captación vital del propio yo" [...]; el sujeto se percibe en su propia "luminosidad", "transparencia" [...]. La persona es el único ser intramundano que tiene conciencia de sí y conciencia de la realidad que lo circunda» ${ }^{52}$. Como hemos podido ver al reflexionar sobre la identidad del hombre como «persona», éste necesita alcanzar una cada vez más perfecta autoafirmación, o sea, debe conocerse, debe tener conciencia de sí. A este tipo de conciencia se le conoce como "conciencia psicológica», tema que más adelante retomaremos; sin embargo, es necesario discernir la otra dimensión de la conciencia presente en el hombre: «la conciencia moral»53.

El hombre es consciente de sí mismo y es consciente de lo que hace. Tener conciencia de lo que se hace es tener conciencia moral. «En el análisis de la

46. Cfr. H.M. YÁNEZ, Esperanza y solidaridad, 312.

47. Cfr. Ibid., 311.

48. JUAN PABLO II, Sollicitudo rei socialis, 38-40.

49. Cfr. BENEDICTO XVI, Spes salvi, 1.

50. H.M. YÁNEZ, Esperanza y solidaridad, 355.

51. Cfr. Ibid., 391.

52. Ibid., 262.

53. Cfr. V. MIRANDA, «Conciencia Moral», en M. VIDAL, ed., Conceptos fundamentales de ética teológica, Madrid: Trotta, 1992, 317-341. 
existencia humana, la conciencia se manifiesta como "autopresencia, vivida en todo acto de pensar, decidir y obrar". Es ella, en cuanto núcleo íntimo del existir del sujeto, el centro de unidad existencial de la persona». ${ }^{54}$ Además, es la conciencia (psicológica y moral) el «lugar» en el cual el hombre puede encontrarse a solas con Dios y donde Dios le habla como a un amigo: «La conciencia es el núcleo más secreto y el sagrario del hombre, en el que éste se siente a solas con Dios, cuya voz resuena en el recinto más íntimo de aquélla». ${ }^{55}$ Según la Gaudium et Spes:

En lo más profundo de su conciencia descubre el hombre la existencia de una ley que él no se dicta a sí mismo, pero a la cual debe obedecer, y cuya voz resuena, cuando es necesario, en los oídos de su corazón, advirtiéndole que debe amar y practicar el bien y que debe evitar el mal: haz esto, evita aquello. Porque el hombre tiene una ley escrita por Dios en su corazón, en cuya obediencia consiste la dignidad humana y por la cual será juzgado personalmente. ${ }^{56}$

El llamado de la voz de Dios que resuena en la conciencia del hombre no es otro que el llamado del amor. En la conciencia el hombre experimenta el interpelo de Dios que lo invita a vivir una vida auténticamente cultual, sincera y agápica. Además, la conciencia guía la libertad del hombre para que ésta siempre busque el bien y la verdad. Pero una conciencia consejera debe ser iluminada, o formada. De ahí que sea necesaria la formación de la conciencia. A su vez, la conciencia es iluminada (formada) bajo el influjo de la gracia divina, que actúa en tantas y tan variadas formas a lo largo de la existencia del hombre. En definitiva, podemos decir que el actuar del hombre, guidado por la conciencia, que a su vez es formada por la gracia divina, será un actuar según la identidad de ser imagen de Dios siempre y cuando tal accionar refleje todos esos valores y principios distintivos de lo cristiano: la fe, la esperanza y la caridad, o sea, una vida teologal. Pero que, además, esa vida teologal se concretice en una experiencia de culto debido, preclara autenticidad y activa caridad.

\section{Desde la antropología Psicológica: Misteryum Dei}

La dignidad de imagen de Dios convierte al hombre en sujeto y objeto de la moral. Su actuar responderá a los parámetros que impone el ser representante de Dios en la tierra. Más aún, el actuar del hombre en su condición de Cristiano implica el reproducir en la propia vida la vida de Cristo: «y no vivo yo, sino que es Cristo quien vive en mí» (Gal 2, 20). Sin embargo, a pesar de tener esa concreta identidad de ser imagen de Dios, de tener el auxilio de la gracia divina, de vivir dentro de un ambiente eclesial que favorece el vivir según el Espíritu, los cristianos, en muchos casos, aún poseen ciertas incoherencias

54. H.M. YÁNEZ, Esperanza y solidaridad, 262.

55. GS, n. 16.

56. Ibid. 
en cuanto a la plenitud de su vivencia cristiana. Por eso en este apartado de nuestro trabajo nos centraremos en el aporte que la antropología psicológica ofrece para comprender mejor la identidad del hombre en cuanto llamado a alcanzar la perfecta semejanza de Dios. El aporte de la psicología ayuda a comprender en cierto modo la razón por la cual el cristiano puede mantener cierta incoherencia de vida aún después de la experiencia salvadora de Cristo.

\subsection{Antropología de la vocación cristiana}

Una primera aproximación a la antropología psicológica la podemos hacer de la mano del gran psicólogo fundador del Instituto de Psicología de la Universidad Gregoriana, el jesuita Luigi Maria Rulla ${ }^{57}$. Este prominente estudioso propone una teoría psico-antropológica, rigurosa y sistemática desde el punto de vista del método científico, centrándose en la identidad del hombre como un ser llamado por Dios destinado a autotrascenderse consistentemente en el amor teocéntrico.

La teoría de Rulla nace y se fundamenta en el análisis del conflicto radicado en el corazón del hombre llamado por Dios a compartir el amor teocéntrico. Tal análisis científico lo realizó Rulla en una investigación que duró muchos años y que dio como resultado la confirmación de las intuiciones fundamentales que este mismo investigador había tenido a partir de la constatación de los numerosos casos de abandono del sacerdocio y la vida consagrada, ocurridos en los años inmediatamente posteriores al Concilio Vaticano II. Entre los conceptos que fundamentan esta teoría y que en cierto modo fueron confirmados por su investigación científica son los siguientes.

\subsubsection{Dialéctica de base}

Desde el punto de vista psico-social y psico-espiritual el hombre manifiesta un contraste en cuanto que siendo un ser abierto a la autotrascendencia (superación de si mismo hacia algo más allá de sí mismo y sobre de si) hacia la verdad, el bien y el amor supremo, se encuentra con el límite de la falibilidad cognoscitiva, decisional, moral y espiritual ${ }^{58}$. Existe, pues, en lo más profundo

57. La teoría de Rulla prácticamente está contenida en las obras que a continuación especificamos. Sin embargo, habiendo creado el Instituto de Psicología de la Universidad Gregoriana, su pensamiento y su investigación se ha sido profundizando y difundiendo ampliamente. Actualmente existe una muy abundante bibliografía que amplía el pensamiento «rulliano». La siguiente es la bibliografía que se ha traducido al español: L.M. RULLA, Psicología profunda y vocación. I: Las personas, Madrid, 21986; ID., Psicología profunda y vocación. II: Las instituciones, Madrid, 1985; ID., Antropología de la vocación cristiana. I: Bases interdisciplinares, Madrid, 1990; ID., Antropología de la vocación cristiana. II: Confirmaciones existenciales, Madrid, 1994; la tercera parte de la antropología de la vocación cristiana está en italiano: L.M. RULLA (ed.), Antropologia della vocazione cristiana. 3. Aspectti interpersonali, Bologna: EDB, 1997; L.M. RULLA - F. IMODA - J. RIDICK, Psicologia del profondo e vocazione. Motivi di entrata e di abbandono, Torino: Marietti, 1977.

58. El fundamento teórico de los conceptos «trascendencia» e «interdisciplinariedad» Rulla los retoma de B.J.F. LONERGAN, Insight: A study of Human Understanding, London: Longmans Green, 1958 (edición española: ID., Insight. Estudio sobre la comprensión humana, Salamanca, 1999), ID., II metodo in teologia, Brescia: Queriniana, 1975 (edición española: ID., Metodo en teología, 
del corazón humano una especie de tensión dialéctica entre un polo actual y un polo ideal del «yo», entre los valores y las necesidades.

\section{a) Yo Actual-Yo ideal}

La estructura psíquica del ser humano gira en torno a un componente definido por Rulla como «Yo ideal», o sea el yo que se trasciende (correspondiendoal modo de percibir el propio deber-ser humano-cristiano $)^{59}$; y sobre el otro componente estructural que le dio el nombre de «Yo actual» 0 yo trascendido (correspondiendo a lo que se es de hecho, nos demos cuenta o no) ${ }^{60}$.

\section{b) Valores y necesidades}

A nivel de contenido psíquico, el contraste estaría entre los valores auto trascendentes (que son atributos del «Yo ideal») ${ }^{61}$ y las necesidades psicosociales (atributos correspondientes del «Yo actual») ${ }^{62}$; es decir, el contraste entre las metas morales y religiosas que apuntan hacia la superación de si por el amor de Dios y del prójimo, y la fuerza egocéntrica que apunta a la satisfacción de sí (como puede ser la necesidad de dependencia afectiva, necesidad de exhibicionismo, necesidad de agresividad, de gratificación sexual, etc.). La presencia de esta dinámica de contraste es a lo que Rulla llama dialéctica de base. ${ }^{63}$

\subsubsection{El hombre en tres dimensiones}

Otro aspecto fundamental de la teoría antropológica de L.M. Rulla es la comprensión del hombre como un ser tridimensional ${ }^{64}$. En verdad son tres modos de ser del mismo sujeto, en el que puede predominar una de estas dimensiones.

\section{a) Primera dimensión: componente consciente moral/espiritual del sujeto}

Es la dimensión que dispone del componente consciente y por tanto el campo de la virtud y al mismo tiempo el pecado, que son los grados de madurez e inmadurez connotadas en la persona. Por ser el componente consciente del sujeto, abre principalmente al horizonte axiológico-teleológico auto trascendente, o bien lo definido por los valores-fines más altos: los valores morales y religiosos. ${ }^{65}$

\footnotetext{
Salamanca, 1988). Cfr. T. HEALY, «La sfida dell'autotrascendenza: antropologia della vocazione cristiana 1 e Bernard Lonergan», en F. IMODA (a cura di), Antropologia interdisciplinare $e$ formazione, Bologna: EDB, 1997, 97-157.

59. Cfr. L.M. RULLA, Antropologia della Vocazione Cristiana 1. Basi interdisciplinari, Bologna: EDB, 1997 [1985], 158-160.

60. Cfr. Ibid., 158-159.

61. Cfr. L.M. RULLA, Antropologia della Vocazione Cristiana 1. Basi interdisciplinari, 151-154; L.M. RULLAF. IMODA - J. RIDICK, Antropologia della Vocazione Cristiana 2. Conferma esistenziale, 64-67.

62. Cfr. L.M. RULLA, Antropologia della Vocazione Cristiana 1. Basi interdisciplinari, 124131.150.430-432.

63. Cfr. Ibid., 142-143.

64. L.M. RULLA - F. IMODA - J. RIDICK, Antropologia della Vocazione Cristiana 2. Conferma esistenziale, Bologna: EDB, 2001 [1986], 45-48.

65. Cfr. L.M. RULLA, Antropologia della Vocazione Cristiana 1. Basi interdisciplinari, 76-78.164168.t
} 


\section{b) Segunda dimensión: componente conjunto consciente/inconsciente del sujeto} Esta dimensión habla del encuentro entre las estructuras conscientes e inconscientes del Yo, con prevalencia de las dinámicas «consistentes» e «inconsistentes» inconscientes -de naturaleza no patológica- sobre las conscientes. Por lo que se abre a un horizonte de valores combinados o conjuntos: los valores auto trascendente y los naturales. Es la dimensión que está en la frontera entre lo consciente virtuoso y lo inconsciente patológico. En ella se juega la dinámica de la incoherencia entre el querer, por ejemplo, vivir como buen cristiano y no poder hacerlo a causa de una «no sé qué fuerza dentro de mí lo impide».66

c)Tercera dimensión: componente prevalentemente inconsciente/patológico El sujeto interactúa en un horizonte axiológico-teleológico delimitado por los valores-fines naturales. Los estándares de comportamiento de un sujeto en el que prevalece esta dimensión no se miden tanto en grado de madurez o inmadurez, sino que se miden más en términos de normalidad y patología. Salvando la complejidad que implica el encuadramiento en el parámetro de lo normal y lo patológico, se puede decir que el sujeto signado en esta dimensión posee una personalidad afectada por conflictos, estilos, síntomas, modos de interactuar con el ambiente externo, que colindan con lo patológico. ${ }^{67}$

\subsubsection{Consistencia en la autotrascendencia del amor teocéntrico}

El centro de la teoría antropológica de Rulla es la autotrascendencia en la consistencia del amor teocéntrico. En otras palabras, el hombre ha sido llamado por Dios a entrar en comunión cada vez más perfecta con Él mediante la autotrascendencia en el amor como valor teocéntrico. Para comprender tal enunciado es importante recordar que para Rulla la vida psíquica tiene una funcionalidad en tres niveles: el nivel Psico-bio-fisiológico (necesidades innatas de alimento, reposo, etc.), el nivel Bio-psico-social (necesidades innatas de amor, afiliación, gratificación sexual, etc.), el nivel Espiritual-racional (compensación, valoración, aceptación y orientación de los valores innatos del primer y segundo nivel). ${ }^{68}$

Además, la personalidad, poseyendo los niveles estructurales del «Yo actual» (lo que uno es actualmente pero que puede ser manifiesto, social y latente) y el «Yo ideal» (con ideales Institucionales y el ideal de Sí), también posee unos contenidos psíquicos representados en los «Valores» (terminales e instrumentales: egocéntricos, filantrópicos, teocéntricos), «Necesidades» (biológicas, psicosociales, espirituales/trascendentes)y «Actitudes» (consistenteseinconsistentes). Tales niveles estructurales y contenidos psíquicos de la personalidad tienen dos modos de manifestarse: modo intrapersonal (psicológico) y modo interpersonal 
(social). La consistencia se detecta en la consonancia entre los valores y las necesidades. Pero el ideal de la vocación cristiana es que la persona se mantenga en un permanente proceso de internalización del amor como valor teocéntrico en modo consistente con las necesidades de calado espiritual trascendente. ${ }^{69}$ Por eso es autotrascendencia en la consistencia del amor teocéntrico.

\subsection{Antropología del misterio}

La otra propuesta antropológica venida desde el campo de la psicología es la presentada por Franco Imoda. Su tesis antropológica se puede enunciar como una «antropología del misterio» ${ }^{70}$. Imoda sostiene que el hombre por ser imagen y semejanza de Dios, el Misterio por antonomasia, es una realidad que no se puede abarcar (definir/comprender) en modo pleno y definitivo de una sola vez. Por lo que el hombre está llamado a profundizar cada vez más en su propio misterio. Y el lugar y el modo como se manifiesta ese misterio es justamente el desarrollo humano bio-psico-espiritual. De tal modo que el hombre está invitado a estar en un permanente dinamismo de autoconocimiento o de auto apropiación de su propio misterio (o desarrollo humano bio-psico-espiritual), dinamismo que Imoda llama «pedagogía del misterio» 0 «mistagogía». ${ }^{71}$

Un término que es preciso definir es “misterio". En sí puede entenderse como una realidad que huirá siempre a cualquier comprensión total. Lo que no quiere decir que sea a la vez algo totalmente oscuro, imposible de comprender, sino una realidad que siendo no fácil de descifrar puede ser percibida y descifrada progresiva y continuamente. El misterio no revela inmediatamente la verdad de lo que esconde, sino que lo revela en modo paulatino. El Misterio por antonomasia es Dios, al que Imoda siempre identifica con la «M» mayúscula y con el artículo determinativo «El»: Dios es «El Misterio». Pero como hemos dicho, el hombre por ser imagen y semejanza de Dios (argumento de las dos primeras partes de este trabajo) es también «misterio», pero en este caso Imoda lo escribe con «m» minúscula, para diferenciarlo del misterio propio de Dios. ${ }^{72}$

\subsubsection{La realidad humana como misterio}

La «antropología del misterio» se fundamenta en el principio teológico del imago Dei: el hombre es «imagen y semejanza de Dios» $(G n 1,27)$. Si Dios es el misterio por antonomasia, entonces el hombre es también «misterio» («la persona es ontológicamente misterio») por ser imagen y semejanza de Dios. Recordemos que el misterio es aquella realidad que se escapa siempre a una comprensión total y definitiva pero que se deja descubrir en modo paulatino,

69. Cfr. L.M. RULLA, Antropologia della Vocazione Cristiana 1. Basi interdisciplinari, 315-316; L.M. RULLA - F. IMODA - J. RIDICK, Antropologia della Vocazione Cristiana 2. Conferma esistenziale, 7-16. 70. Cfr. F. IMODA, Sviluppo Umano. Psicologia e Mistero, Bologna: EDB, 2005. Esta es sin duda la obra fundamental donde se encuentra la tesis de Imoda. Sin embargo, existe una abundante bibliografía que explicita y profundiza esa propuesta antropológica.

71. F. IMODA, Sviluppo Umano, 440.

72. “La persona é ontologicamente mistero” afirma Imoda. Cfr. F. IMODA, Sviluppo Umano, 475. 
progresivo y permanente. «El misterio no revela inmediata y definitivamente la verdad sino que sólo la deja entrever». ${ }^{73}$

Ahora bien, según el dato revelado «Dios es amor» (1Jn 4,8), por tanto la esencia del misterio del hombre es también el amor: el hombre realiza su verdadera identidad solo en el amor. Pero no cualquier amor, sino sólo en el amor de Dios, o sea el amor teocéntrico. Por eso el hombre experimenta esa permanente dialéctica de base, pues ya que «el misterio que está en él» lo mantiene inquieto y proyectado en modo permanente en búsqueda de su plena identidad que solo la encuentra frente al Dios amor. La lucha interior en el hombre será permanente mientras esté en este mundo. Más aún, la lucha se convierte en drama/tragedia cuando el hombre no está en sintonía con su verdadera identidad, o sea cuando no mantiene en sintonía con el amor de Dios. La inconsistencia en el amor teocéntrico ofusca el misterio del hombre y lo introduce en una dramática lucha de autodegradación y sufrimiento. El hombre es feliz sólo cuando «es lo que realmente está llamado a ser». ${ }^{74}$ El misterio siempre puja por concretizarse en el hombre.

\subsubsection{El desarrollo como lugar del misterio}

«El desarrollo es pues el lugar donde el misterio toma forma en modo auténtico o inauténtico». ${ }^{75}$ Vivir el misterio auténticamente significa vivir el desarrollo como tal, o sea, aceptar la vocación del ser humano a ponerse como una mediación dinámica entre su miseria y su dignidad, entre su ser y su no ser, entre su ser temporal y su ser en el eterno, entre su ser corporal y su ser espiritual, entre su ser finito y su ser infinito. Vivir el misterio es ser lo que se está llamado a ser. En el desarrollo humano el misterio no solo se manifiesta, sino también se configura o modela al mismo tiempo. ${ }^{76}$

Por ser justamente el desarrollo humano el lugar donde se manifiesta y actualiza el misterio que el hombre es, resulta que negar o suprimir el desarrollo implicar morir, significa anular la dignidad del mismo hombre. Sin embargo, aceptar el desarrollo implica igualmente un morir, un no estar conforme y entrar en una lucha permanente y en un expandirse en el continuum del misterio hacia la consecución de la máxima cercanía y asimilación del Misterio absoluto que es Dios.

\footnotetext{
73. A. MANENTI, Vivere gli Ideali 2. Fra senso posto e senso dato, Bologna: EDB, 2003, 27-30. «Mistero, nell' interpretazione qui davvero originale di Imoda, non é il tenebroso, l'inaccessibile, l'indicibile, come spesso si é indotto a pensare, o ció che si puó al limite solo contemplare, devotamente, o di fronte al quale si deve per forza rimanere a distanza, molto umilmente..., ma é il luminoso, anzi, il luminosissimo, cosí pieno di luce che il nostro occhio no lo puó fissare direttamente, per questo e solo per questo eccesso di luce no lo si puó afferrare né capire inmediatamente”, A. CENCINI, «Psicologia e mistero: un rapporto inedito e fecondo" in A. MANENTI - S. GUARINELLI - H. ZOLLNER, Persona e Formazione. Riflessioni per la pratica educativa e psicoterapeutica, Bologna: EDB, 2007, 247.

74. F. IMODA, Sviluppo Umano, 53.

75. Ibid., 435.

76. Cfr. F. IMODA, Riscopri il mistero che é in te, Roma: ADP, 2002, 15.
} 
La misma experiencia de la interioridad humana deja entrever algunas ventanas por medio de las cuales el misterio se percibe (el tiempo, el juegoreír, el buscar, el dolor, la soledad, la insatisfacción) y es a través de algunas mediaciones (cognitiva, afectiva, interpersonal) que se actualiza ${ }^{77}$. Ciertamente el desarrollo humano toma en cuenta la altura, la profundidad y la amplitud del misterio. 0 mejor, el misterio se actualiza mediante la altura (conscienciarazón), profundidad (afectividad-corazón) y amplitud (alteridad-persona) del ser humano en desarrollo.

\subsubsection{Los parámetros y las mediaciones del misterio}

Lo apenas esbozado en el párrafo anterior requiere una mayor atención. La propuesta teórica de Imoda describe al hombre como misterio que se actualiza en el mismo desarrollo humano. Pero para comprender cómo se realiza el desarrollo humano y se manifiesta el misterio, Imoda propone atender ciertos parámetros: la alteridad, la temporalidad y los estadios ${ }^{78}$.

\section{a) El parámetro de la alteridad}

Este parámetro permite reconocer al hombre como persona, como relacionalidad, en cuanto que es imago Dei. Esta alteridad inicia con el relacionarse consigo mismo, con su Sí (Self), y por tanto implica también una dinámica cognoscitiva: conocerse a sí mismo (gnotou auton). Pero la dinámica cognoscitiva de sí mismo incluye el contacto con el otro (alter) con quien logra obtener la propia y auténtica identidad (el «síi -self- se forma sólo frente a un «otro»): te conoces a ti mismo conociendo e interactuando con el otro. $Y$ esa alteridad con un «otro» está igualmente mediada por el componente afectivo. Además, toda la dinámica interactiva con un "otro» trasporta hacia un «Otro» absoluto, definitivo. La alteridad que necesita el hombre no se agota en la alteridad con un «otro» relativo y limitado -aunque a su vez sea un misterio, o cuanto menos, en palabras de K. Rahner, un «absoluto relativo»- sino que tiende hacia un «Otro» absoluto, o El Misterio por antonomasia, Dios.

\section{b) El parámetro de la temporalidad}

Es el área de la acción, de la voluntad y de la libertad, el área conativa ${ }^{79}$. La temporalidad expresa, en el momento presente concreto, cómo la voluntad se ejercita, teniendo en cuenta que el hombre se actualiza en el tiempo como un resultado del pasado y como un proyecto para el futuro. En medio de esa tensión temporal (entre pasado y futuro) es que el hombre está llamado a ejercer su libertad y a actuar según su voluntad. Aquí entran las categorías éticas y morales, que son connaturales al hombre y que se configuran en ese desarrollo humano, que también manifiestan y actualizan el misterio. ${ }^{80}$

77. Cfr. F. IMODA, Sviluppo Umano, 21-48.

78. Cfr. Ibid., 99-135.

79. Cfr. F. IMODA, Riscopri il mistero che é in te, 22.

80. Un interesante estudio sobre la relación entre moral y psicología lo ofrece B. KIELY, Psicologia e Teologia Morale. Linee di convergenza, Casale Monferrato: marietti, 1982. También A. FUMAGALLI, 
El dinamismo conativo está condicionado por el pathos y la gnosis que a su vez afectan la alteridad: conocimiento y afectividad determinan la acción. Al momento de actuar se debe tomar en cuenta siempre al otro (de ahí el componente ético-moral), pues lo conativo está limitado también por el otro, por la alteridad. En otras palabras, el parámetro de la temporalidad no se desentiende del parámetro de la alteridad.

\section{c) El parámetro de los estadios}

Este parámetro abarca el área afectivo-motivacional con todas sus articulaciones. Pero sobre todo toca el desarrollo humano en su aspecto procesual y dinámico. La «evolutividad», que es una característica del hombre en su condición mistérica -puesto que el misterio no se presenta de una vez por todas-, tiene que ser siempre respetada y tomada en cuenta. El desarrollo humano toma muy en cuenta la ley de la gradualidad. Por eso es necesario tener paciencia en el proceso de crecimiento para no bloquear el efectivo desarrollo de la persona y lograr sobre todo encontrar aquella dimensión del misterio que, propio ahí, en la lentitud del desarrollo (a causa de las crisis, las dudas, las inquietudes más profundas, etc.), puede encontrarse una gran riqueza. Sin duda que las crisis pueden ser también el lenguaje que el misterio usa para manifestarse, y ellas marcan el ritmo del desarrollo auténtico. Este parámetro hace cumplir aquello de «despacio que voy de prisa» ${ }^{81}$. Precisamente es en esta dinámica gradual que se introduce la vida afectiva del ser humano, pues el amor tiene que ser purificado paso a paso, hasta llegar al amor de autotrascendencia teocéntrica.

Por último, es necesario insistir en las mediaciones que el misterio usa para hacerse presente y palpable en el desarrollo humano: las dimensiones cognitiva, afectiva e interpersonal de la persona. Como hemos insinuado en los anteriores párrafos, cada parámetro se conecta con una mediación: el parámetro de la alteridad se relaciona con la mediación cognitiva, el parámetro de la temporalidad se relaciona con la mediación interpersonal y el parámetro de los estadios tiene que ver con la mediación emotiva ${ }^{82}$. Los parámetros determinan el camino del desarrollo y las mediaciones lo manifiestan y concretizan. Y precisamente en ese desarrollo es que el misterio, presente en el hombre, se actualiza.

\section{Conclusión}

Al finalizar este recorrido por las principales líneas de comprensión antropológica que desde una perspectiva interdisciplinar hemos realizado, nos permite concluir que esta antropología ofrece incalculables posibilidades de aplicación en el terreno educacional. Hemos analizado la grandeza del ser del hombre y la razón última de donde le viene esa grandiosidad. Hemos pasado también a revisar el actuar del hombre y hemos descubierto los principios fundamentales

«Il parametro della temporalitá e la sua importanza per la teologia morale» en A. MANENTI - S. GUARINELLI - H. ZOLLNER, Persona e Formazione, 207-227.

81. Cfr. F. IMODA, Riscopri il mistero che é in te, 23-25.

82. Cfr. F. IMODA, Sviluppo Umano, 179-431. 
desde donde se ha de valorar el acto humano. Conociendo lo más hondo del ser del hombre y lo que está a la base de su actuar nos hemos preguntado por qué muchas veces el acto no sigue al ser (ya que el ser debería evidenciarse en el actuar) y la respuesta la hemos encontrado en el terreno psicológico: no autotrascenderse en el amor y no permitir un sano desarrollo del propio yo mediante la actualización de todas las potencialidades personales. Educar a la luz de esta antropología es la tarea que nos queda.

Creemos oportuno señalar e insistir que uno de los principios que deberán estar a la base de un sistema educativo es el "principio antropológico". Todo debe partir del hombre y estar en función del hombre. El hombre debe ser la medida de todas las cosas en el quehacer educativo. El mercado deberá quedar en un segundo plano, puesto que por mucho tiempo éste ha guiado el quehacer educativo (instruir para ofrecer mano de obra cualificada). En la comprensión del hombre como "principio-fundamento" del quehacer educativo es necesario señalar la triple dimensión que tiene todo ser humano: su ser trascendente, su ser personal-individual y su ser social. Tales dimensiones deberán articularse y respetarse en su complementariedad.

Si el proceso educativo se limita a ver al hombre como un ser de inmanencias, o sea, como una cosa entre otras cosas, sin respetar su carácter trascendente y su potencial de trascendencia, entonces entorpece el genuino desarrollo de su ser; casi podríamos decir que lo atrofia existencialmente, ya que la trascendencia, o autotrascendencia, es requisito para que el hombre pueda llegar a ser plenamente sí mismo. Por otra parte, una educación que se enfoque sólo en el ámbito individual ofrecerá un producto final (el hombre educado) con una seria limitación: el egoísmo. La educación que enfoca sólo la dimensión social en detrimento de la individualidad, despersonaliza y crea un hombre masa, sin identidad propia pues su identidad la encuentra solo en la masa. La tarea educativa debe apuntar al justo equilibrio entre lo trascendente, lo individual y lo social en el hombre, para que así sea educado en su integridad: la dimensión creativa y emprendedora debe complementarse con la dimensión solidaria, corresponsable y comprometida con el otro, lo que a su vez lo hace autotrascenderse. Si es así, la educación estará partiendo de sólidos principios.

Debemos decir, entonces, que la realidad salvadoreña demanda de la educación la centralidad de la persona vista integralmente. El "salvadoreño educado" es el que remodelará la trágica realidad social, familiar y personal. Educando al hombre es como se salva la sociedad y la familia. La persona debe estar al centro, como lo hemos ya expresado. Si como nación se le apostara seriamente a la educación, adoptándola como política de Estado, con un enfoque antropológico coherente, sin duda sería la solución a los múltiples problemas que estamos afrontando. Se suele decir como cifra estándar que un país debe invertir en educación por lo menos el $6 \%$ del PIB para poder salir del subdesarrollo. En Europa se gasta más del 8\%, pero en Cuba se invierte el 
13.8\% del PIB. En El Salvador, para el año 2013, sólo se invirtió un vergonzoso $3.3 \%$ del PIB constituyéndose en una de los más bajas inversiones en educación en Latinoamérica ${ }^{83}$. La educación es la solución sin lugar a dudas. Pero convencernos de que así es y destinar todos los recursos para ello es un salto de cualidad que todavía no damos. El Estado debe comprometerse seriamente y todas las instancias nacionales lo deben apoyar. Todos debemos convencernos que la educación es la solución.

Pero no bastaría con que se enfilen todos los recursos y estrategias para lograr una más amplia educación en el país. Es necesario, y no nos cansaremos en insistir, que a la base de esa educación esté un sólido fundamento antropológico. Creemos haber delineado en este artículo algunas ideas basilares de esa mejor comprensión del hombre que hay que educar. Ahora sólo queda la tarea de comenzar a aplicar esos fundamentos. Al respecto creemos que el terreno por donde comenzar ese trabajo de aplicación está en dos grandes campos: el currículum nacional y los procesos catequéticos parroquiales. Una clara visión del hombre es indispensable para elaborar un adecuado currículum educativo y una más precisa y pertinente catequesis. Sin duda que ello ayudaría a reelaborar nuestro desgarrado tejido social. Las luces que hemos encontrado en esta investigación nos ofrecen un mejor panorama para lanzarse a la gran aventura de la educación del salvadoreño que queremos educar y así recrear un tejido social digno de este noble pueblo.

\section{Bibliografía}

Aa.Vv. Comentario bíblico San Jerónimo, I, Madrid: Cristiandad, 1971.

Aa.Vv. Dizionario Esegetico del Nuovo Testamento, I, Brescia: Paideia Editrice, 1995.

Aa.Vv. Enciclopedia De La Biblia, IV, Barcelona: Ediciones Garriga, 1963.

Bandera, a., Comunión Eclesial y Humanidad, Salamanca: San Esteban, 1978.

Barba Avila, C., Teología de La Imagen de Dios en San Hilario De Poitiers, Navarra: Excerpta XLVI, 2004.

Benedicto XVI, Spes Salvi (2007).

Boorjamra, J., «Original sin according to St Maximus the Confessor» In Saint Vladimir'S Theological Quarterly 20 (1976)

Compagnoni, F. - Piana, G. - Privitera, s., Dirs., Nuevo diccionario de teología moral, Madrid: Paulinas, 1992.

De Lubac, H., El Misterio de lo sobrenatural, Madrid: Encuentro, 1991.

Denzinger, H. - Hünermann, p., El magisterio de la Iglesia, 338ª . Ed., España: Herder, 2006.

Flecha Andrés, J.R., Teología moral fundamental, Madrid: BAC, 1994.

Flecha Andrés, J.R., Moral de la persona, Madrid: BAC.

Freyer, J. B., Homo viator: l'uomo alla luce della storia della salvezza, un'antropologia teologica in prospettiva francescana, Bologna: EDB, 2008.

Ghirlanda, G., Il diritto nella chiesa. Mistero di comunione, Roma: San Pablo, 1990.

Häring, b., La ley de Cristo, I, Barcelona: Herder, 1963.

83. Cfr. Informe MINED 2013. 
Imoda, f., Sviluppo Umano. Psicologia e Mistero, Bologna: EDB, 2005.

Imoda, f., Riscopri il mistero che é in te, Roma: ADP, 2002.

Ladaria, I.F., Jesucristo, Salvación de todos, San Pablo, Madrid, 2007.

Lonergan, b.J.F., Insight: A Study Of Human Understanding, London: Longmans Green, 1958.

Lonergan, b.J.F., Metodo en teología, Salamanca, 1988.

Lorda, j.L., Antropología Cristiana: del Concilio Vaticano II a Juan Pablo II, Palabra, Madrid, 1996.

Juan Pablo II, Redemptoris Hominis (1979)

Juan Pablo II, Catecismo de la Iglesia Católica (1992).

Juan Pablo II, Sollicitudo rei sociales (1987).

Juan Pablo II, Familiaris Consortio (1981).

Juan Pablo II, Christifedele Laici (1988).

Kiely, b., Psicologia e Teologia Morale. Linee di convergenza, Casale Monferrato: Marietti, 1982.

Manenti, a. - Guarinelli, s.- Zollner, h., Persona e Formazione. Riflessioni per la pratica educativa e psicoterapeutica, Bologna: EDB, 2007.

Manenti, a., Vivere gli ideali 2. Fra senso posto e senso dato, Bologna: EDB, 2003.

Pontificia Comisión Bíblica, Bibbia e Morale. Radici bibliche del 'agire cristiano, Ciudad Del Vaticano: Editrice Vaticana, 2008.

Rahner, k., Oyentes de la Palabra, Barcelona: Herder, 1967.

Rulla, L.M., Psicología profunda y vocación. I: las personas, Madrid, 21986.

Rulla, L.M., Psicología profunda y vocación. li: las instituciones, Madrid, 1985.

Rulla, L.M., Antropología de la vocación cristiana. I: bases interdisciplinares, Madrid, 1990.

Rulla, L.M., Antropología de la vocación cristiana. li: Confirmaciones existenciales, Madrid, 1994.

Rulla L.M., (Ed.), Antropologia della vocazione cristiana. 3. Aspectti interpersonali, Bologna: EDB, 1997.

Rulla L.M. - Imoda, f. - Ridick, j., Psicologia del profondo e vocazione. Motivi di entrata e di abbandono, Torino: Marietti, 1977.

Rulla, L.M., Antropologia della Vocazione Cristiana 1. Basi Interdisciplinari, Bologna: EDB, 1997.

Rulla, L.M.- Imoda, f. - Ridick, j., Antropologia della vocazione cristiana 2. Conferma esistenziale, Bologna: EDB, 2001.

Sesbüé, b., Historia de los dogmas. El hombre y su salvación, II, España: Secretariado Trinitario, 1996.

Vidal, M., Moral de actitudes, i, Madrid: ps editorial, 1981.

Vidal, M., Ed., Conceptos fundamentales de ética teológica, Madrid: trotta, 1992.

Yánez, H. M., Esperanza y Solidaridad. Una fundamentación antropológico-teológica de la moral cristiana en la obra de Juan Alfaro, Madrid: Publicaciones Up Comillas, 1999. 